\title{
Clinical Impact of Supplementation of Vitamins B1 and C on Patients with Sepsis- Related Acute Respiratory Distress Syndrome
}

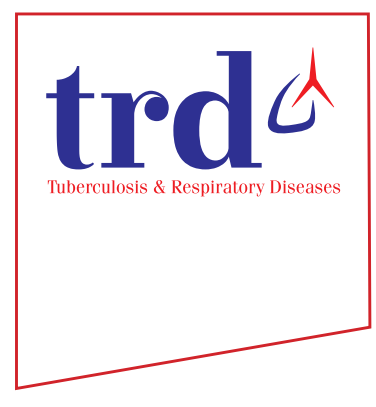

\author{
Jung-Wan Yoo, M.D. ${ }^{1}{ }^{(i)}$, Rock Bum Kim, M.D., Ph.D. ${ }^{2}$, Sunmi Ju, M.D. ${ }^{1}$, Seung Jun Lee, M.D., \\ Ph.D. ${ }^{1,3}$, Yu Ji Cho, M.D., Ph.D. ${ }^{1,3}$, Yi Yeong Jeong, M.D., Ph.D. ${ }^{1,3}$, Jong Deog Lee, M.D., Ph.D. ${ }^{1,3}$ and \\ Ho Cheol Kim, M.D., Ph.D., ${ }^{3,1}$ \\ ${ }^{1}$ Department of Internal Medicine, Gyeongsang National University Hospital, Jinju, ${ }^{2}$ Regional Cardiocerebrovascular \\ Disease Center, Gyeongsang National University Hospital, Jinju, ${ }^{3}$ Gyeongsang National University School of Medicine, Jinju, \\ ${ }^{4}$ Department of Internal Medicine, Gyeongsang National University Changwon Hospital, Changwon, Korea
}

Background: Although few studies have reported improved clinical outcomes with the administration of vitamin B1 and $\mathrm{C}$ in critically ill patients with septic shock or severe pneumonia, its clinical impact on patients with sepsis-related acute respiratory distress syndrome (ARDS) remains unclear. The purpose of this study was to evaluate the association with vitamin B and C supplementation and clinical outcomes in patients with ARDS.

Methods: Patients with ARDS requiring invasive mechanical ventilation, admitted to the medical intensive care unit (ICU) were included in this study. Clinical outcomes were compared between patients administered with vitamin B1 (200 $\mathrm{mg} /$ day) and C (2 g/day) June 2018-May 2019 (the supplementation group) and those who did not receive vitamin B1 and C administration June 2017-May 2018 (the control group).

Results: Seventy-nine patients were included. Thirty-three patients received vitamin B1 and C whereas 46 patients did not. Steroid administration was more frequent in patients receiving vitamin B1 and C supplementation than in those without it. There were no significant differences in the mortality between the patients who received vitamin $\mathrm{B} 1$ and $\mathrm{C}$ and those who did not. There were not significant differences in ventilator and ICU-free days between each of the 21 matched patients.

Conclusion: Vitamin B1 and C supplementation was not associated with reduced mortality rates, and ventilator and ICU-free days in patients with sepsis-related ARDS requiring invasive mechanical ventilation.

Keywords: Sepsis; Acute Respiratory Distress Syndrome; Vitamin B1; Vitamin C

\section{Address for correspondence: Ho Cheol Kim, M.D., Ph.D.}

Department of Internal Medicine, Gyeongsang National University

Changwon Hospital, Gyeongsang National University School of

Medicine, 11 Samjeongja-ro, Seongsan-gu, Changwon 51472, Korea

Phone: 82-55-214-3730, Fax: 82-55-214-8618

E-mail: hochkim@gnu.ac.kr

Received: Feb. 10, 2020

Revised: Apr. 19, 2020

Accepted: May. 13, 2020

Published online: Jun. 16, 2020

(c) It is identical to the Creative Commons Attribution Non-Commercial License (http://creativecommons.org/licenses/by-nc/4.0/).

\section{Introduction}

Sepsis is a life-threatening condition accompanied by organ dysfunction caused by a dysregulated host response to infection $^{1}$. Mortality rate ranges from $10 \%$ in patients with sepsis to more than $40 \%$ in patients with septic shock. Acute respiratory distress syndrome (ARDS) is a fatal condition that commonly develops in patients with sepsis. ARDS is not uncommon reason for intensive care unit (ICU) admission and require invasive mechanical ventilation (IMV) ${ }^{2}$. The mortality rate of ARDS still remains high despite of advances in critical care medicine and research ${ }^{2,3}$. The key pathogenetic mechanism of ARDS is the complex inflammatory response ${ }^{4}$, which results in hypoxemia and abrogation of aerobic metabolism. Adjunct 
pharmacological therapies in patients with ARDS have been tried, but their clinical benefit is yet to be proven robustly ${ }^{5-7}$.

Vitamin $\mathrm{B} 1$ is involved in aerobic metabolism ${ }^{8}$, and vitamin $\mathrm{C}$ has anti-inflammatory and anti-oxidative effects ${ }^{9,10}$. Vitamin $\mathrm{B} 1$ and $\mathrm{C}$ deficiencies have been reported in critically ill patients with sepsis ${ }^{11,12}$. Two retrospective studies have reported that intravenous administration of vitamin $\mathrm{B} 1$ or $\mathrm{C}$ improves clinical outcomes in critically ill patients with septic shock or severe pneumonia ${ }^{13,14}$. However, recent studies did not show the clinical benefits of the combination of vitamin B1, C, and hydrocortisone ${ }^{15,16}$. The clinical implication of intravenous administration of vitamin $B$ and $C$ on patients with sepsis-related ARDS was not elucidated.

The aim of this study was to evaluate the clinical impact of vitamin B and C supplementation in patients with sepsisrelated ARDS.

\section{Materials and Methods}

\section{Patients}

From June 2017 to May 2019, the clinical data of patients older than 18 year olds with sepsis-related ARDS who received IMV and admitted at the 13-bed medical ICU (MICU) of the tertiary hospital were retrospectively reviewed. All patients under IMV met the Berlin criteria for ARDS ${ }^{17}$. Since June 2018, vitamin B1 and C supplementation was initiated in MICU. Patients at 1-year before vitamin B1 and C supplementation were designated to the control group, whereas those at 1-year after vitamin B1 and C supplementation was to the supplementation group. The characteristics and clinical outcomes were compared between the two groups.
The total supplementation of vitamin B1 was $200 \mathrm{mg} /$ day as recommended by the guideline ${ }^{18}$. Vitamin B1 was intravenously infused $50 \mathrm{mg}$ every 6 hours. The optimal dose of vitamin $C$ has not been established, although several studies have reported that high dose vitamin $\mathrm{C}$ administration was effective in critically ill patients. Presently, we gave intravenously administered a total $2 \mathrm{~g}$ of vitamin $\mathrm{C}$ in accordance with a recent pharmacokinetic study which showed that at least $2 \mathrm{~g}$ of vitamin $\mathrm{C}$ was sufficient to maintain vitamin $\mathrm{C}$ concentration in the blood of critically ill patients ${ }^{19}$. Vitamin $\mathrm{C}$ was intravenously infused $500 \mathrm{mg}$ every 6 hours. Vitamin B1 and C was given intravenously until death at MICU, reversal of shock, until MV weaning or discharge at MICU.

\section{Data collection}

Baseline (age, sex, body mass index, comorbidities) and clinical characteristics (presence of shock, acute kidney injury, and management) were assessed. The severities of illness Acute Physiology and Chronic Health Evaluation (APACHE) II score, and Sequential Organ Failure Assessment (SOFA) score were noted. Additionally, the data of various laboratory parameters (white cell count, hemoglobin, platelet, C-reactive protein, albumin, procalcitonin, partial pressure of carbon dioxide, and partial pressure of oxygen/fractionated inspired oxygen) were collected. Moreover, clinical outcomes (ventilator-free and ICU-free day at 30 days, mortality) were analyzed.

This study was approved by the Institutional Review Board of Gyeongsang National University Hospital (IRB No. 201903-001). The requirement of informed consent was waived because of the retrospective nature of the study. The study was conducted in accordance with the ethical standards of institutional and/or national research committees and ad-

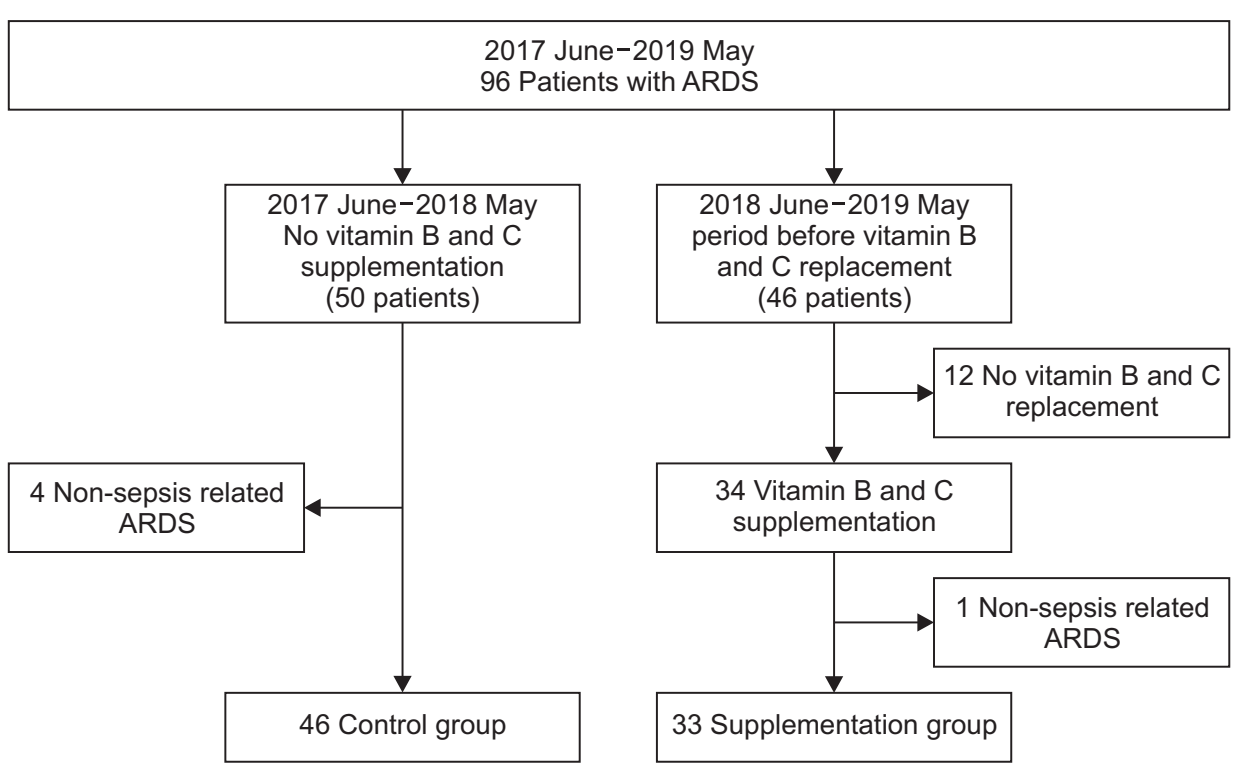

Figure 1. Patients in this study. ARDS: acute respiratory distress syndrome. 
hered to the tenets of the Declaration of Helsinki and its later amendments or comparable ethical standards.

\section{Statistical analysis}

Categorical variable are expressed as and compared with chi-square or Fisher's exact tests. Continuous variables are presented as median and interquartile range or as mean \pm standard deviation, unless indicated otherwise, and compared with Mann-Whitney U or Student's t-tests. Factors associated with mortality were evaluated with Cox proportional hazards regression analysis. Propensity score matching method was performed to consider for the differences in baseline and clinical characteristics. Matched variables were age, gender, APACHE II score, SOFA score, use of neuromuscular blocking (NM) blockers, steroid, and prone position. Based on the standard deviation of the logit of the estimated propensity score, 1:1 matching was performed using the nearest-neighbor method with a caliper width of 0.2 in a pairwise manner All tests of significance were two-tailed. A p-value of 0.05 was considered statistically significant. All data were analyzed with SPSS software version 18.0 (SPSS Inc., Chicago, IL, USA).

Table 1. Comparison of the baseline and the clinical characteristics between the patients with vitamin B1 and C and those without

\begin{tabular}{|c|c|c|c|c|}
\hline Variable & $\begin{array}{c}\text { Total } \\
(n=79)\end{array}$ & $\begin{array}{l}\text { Vitamin } B 1 \text { and } C \\
(n=33)\end{array}$ & $\begin{array}{l}\text { No vitamin } \\
\quad(n=46)\end{array}$ & p-value \\
\hline Age, yr & $70(59-79)$ & $66(55.5-81)$ & $73.5(63-79)$ & 0.257 \\
\hline Male sex & $54(68.4)$ & $20(60.6)$ & $34(73.9)$ & 0.210 \\
\hline BMI, $\mathrm{kg} / \mathrm{m}^{2}$ & $21.8(20.1-24.9)$ & $22.5(20.7-26.2)$ & $21.6(19.7-24.2)$ & 0.179 \\
\hline Diabetes mellitus & $23(29.1)$ & $10(30.3)$ & $13(28.3)$ & 0.844 \\
\hline Chronic kidney disease & $7(8.9)$ & $4(12.1)$ & $3(6.5)$ & 0.443 \\
\hline Chronic liver disease & $12(15.2)$ & $5(15.2)$ & $7(15.2)$ & 0.994 \\
\hline Cerebrovascular disease & $14(17.7)$ & $4(12.1)$ & $10(21.7)$ & 0.270 \\
\hline Active malignancy & $7(8.9)$ & $1(3.0)$ & $6(13)$ & 0.229 \\
\hline COPD & $5(6.3)$ & $3(9.1)$ & $2(4.3)$ & 0.644 \\
\hline APACHE II & $27(23-33)$ & $26(20.5-32.5)$ & $30(24-33.3)$ & 0.226 \\
\hline SOFA & $13(10-15)$ & $13(11-15)$ & $12(10-14.3)$ & 0.462 \\
\hline Cause of sepsis & & & & 0.671 \\
\hline Pneumonia & $73(92.4)$ & $30(90.9)$ & $43(93.5)$ & \\
\hline Pancreatico-biliary origin & $4(5.1)$ & $1(3)$ & $3(6.5)$ & \\
\hline Others & $2(2.5)$ & $2(6.1)$ & & \\
\hline Septic shock & $57(72.2)$ & $21(63.6)$ & $36(78.3)$ & 0.153 \\
\hline AKI & $47(59.5)$ & $18(54.5)$ & $29(63)$ & 0.448 \\
\hline RRT & $20(25.3)$ & $7(21.2)$ & $13(28.3)$ & 0.477 \\
\hline \multicolumn{5}{|l|}{ MV parameters } \\
\hline TV (PBW), mL/kg & $7.4(6.2-8)$ & $7.5(6.4-8.5)$ & $7.1(6.1-7.9)$ & 0.272 \\
\hline PEEP & $8(5-10)$ & $7(5-10)$ & $8(5.8-10.5)$ & 0.071 \\
\hline $\mathrm{FiO}_{2}$ & $80(60-100)$ & $80(70-100)$ & $80(60-92.5)$ & 0.295 \\
\hline Use of NM blockers & $25(31.6)$ & $18(54.5)$ & $7(15.2)$ & $<0.001$ \\
\hline Steroid & $39(49.4)$ & $23(69.7)$ & $16(34.8)$ & 0.002 \\
\hline Prone position & $11(13.9)$ & $8(24.2)$ & $3(6.5)$ & 0.045 \\
\hline ECMO & $4(5.1)$ & $2(6.1)$ & $2(4.3)$ & 1.000 \\
\hline
\end{tabular}

BMI: body mass index; COPD: chronic obstructive pulmonary disease; APACHE: Acute Physiology and Chronic Health Evaluation; SOFA: Sequential Organ Failure Assessment; AKI: acute kidney injury; RRT: renal replacement therapy; MV: mechanical ventilation; TV: tidal volume; PBW: predicted body weight; PEEP: positive end-expiratory pressure; $\mathrm{FiO}_{2}$ : fractioned inspired oxygen; NM: neuromuscular blocking; ECMO: extracorporeal membrane oxygenation. 


\section{Results}

\section{The characteristics of the patients}

During the 2-year study period, 96 patients with ARDS were admitted to the MICU (Figure 1). From June 2017 to May 2018, before vitamin $\mathrm{B} 1$ and $\mathrm{C}$ supplementation, 50 patients were admitted because of ARDS and sepsis-related ARDS was in 46 patients (control group). From June 2018 to May 2019, 46 patients with ARDS were admitted to MICU and 34 patients (73.9\%) of them received vitamin B1 and C supplementation (supplementation group) with exception of one patient, 33 patients were diagnosed with sepsis-related ARDS. The characteristics were compared between the control $(n=46)$ and supplementation $(\mathrm{n}=33)$ groups and the data are shown in Table 1. Median duration of vitamin B1 and C was 6 days and interquartile range was 3.5-10 days.

The median age of patients was 70 years old and $70 \%$ among them were men. There was no significant difference in the baseline characteristics, and severity of illness scores. In mechanical ventilator parameters, there was no significant difference in two groups. The NM agents were more used in vitamin Bl and C supplementation group than in control group.

Steroid administration and prone positioning of patients were significantly frequent in the supplementation group than those in control group. There were no significant differences in the proportion of patients who had acute kidney injury and or those who underwent renal replacement therapy or extracorporeal membrane oxygen therapy.

The values of laboratory parameters and severity of ARDS were compared and are shown in Table 2 . Regarding the values of laboratory parameters, no significant differences were observed between the two groups. There was a higher trend toward severe ARDS in the supplementation group than control group ( $57.6 \%$ vs. $37 \%$, $\mathrm{p}=0.095)$.

Table 2. Comparison of the laboratory results between the patients with vitamin $\mathrm{B} 1$ and $\mathrm{C}$ and those without

\begin{tabular}{|c|c|c|c|c|}
\hline Variable & $\begin{array}{c}\text { Total } \\
(n=79)\end{array}$ & $\begin{array}{l}\text { Vitamin } B 1 \text { and C } \\
\qquad(n=33)\end{array}$ & $\begin{array}{l}\text { No vitamin } \\
(n=46)\end{array}$ & p-value \\
\hline $\mathrm{WBC}, \times 10^{3} / \mathrm{mm}^{3}$ & $15.0(7.1-22.4)$ & $13.4(6.6-24.7)$ & $15.3(9.2-21.7)$ & 0.960 \\
\hline $\mathrm{Hb}, \mathrm{g} / \mathrm{dL}$ & $11(9.5-12.3)$ & $10.3(9-11.4)$ & $11.2(9.6-12.5)$ & 0.106 \\
\hline Platelet, $\times 10^{3} / \mathrm{mm}^{3}$ & $186(98-262)$ & $186(89.5-251)$ & $193(123-282)$ & 0.588 \\
\hline Albumin, g/dL & $2.6(2.2-3)$ & $2.6(2.2-3)$ & $2.8(2.1-3)$ & 0.731 \\
\hline CRP, mg/dL & $17.2(11.2-28.2)$ & $15.9(10.6-29.9)$ & $19.7(10.9-27.8)$ & 0.669 \\
\hline $\mathrm{PaCO}_{2}, \mathrm{~mm} \mathrm{Hg}$ & $39(34-45)$ & $38(34.5-45.5)$ & $39.5(33-45)$ & 0.746 \\
\hline $\mathrm{P} / \mathrm{F}$ ratio & $106.7(85-139.8)$ & $92.5(81.6-133.9)$ & $109.4(87.9-143.4)$ & 0.166 \\
\hline Severity of ARDS & & & & 0.095 \\
\hline Mild & $3(3.8)$ & 0 & $3(6.5)$ & \\
\hline Moderate & $40(50.6)$ & $14(42.4)$ & $26(56.5)$ & \\
\hline Severe & $36(45.6)$ & $19(57.6)$ & $17(37)$ & \\
\hline
\end{tabular}

WBC: white blood cell; $\mathrm{Hb}$ : hemoglobin; $\mathrm{CRP}$ : C-reactive protein; $\mathrm{PaCO}_{2}$ : partial pressure of carbon dioxide; P/F: partial pressure of oxygen/ fractioned inspired oxygen; ARDS: acute respiratory distress syndrome.

Table 3. Comparison of the clinical outcomes between the patients with vitamin $\mathrm{B} 1$ and $\mathrm{C}$ and those without

\begin{tabular}{|lcccc|}
\hline \multicolumn{1}{|c}{ Variable } & $\begin{array}{c}\text { Total } \\
(\mathbf{n = 7 9 )}\end{array}$ & $\begin{array}{c}\text { Vitamin B1 and C } \\
(\mathbf{n}=\mathbf{3 3})\end{array}$ & $\begin{array}{c}\text { No vitamin } \\
(\mathbf{n = 4 6 )}\end{array}$ & p-value \\
\hline 14-Day mortality & $37(46.8)$ & $15(45.5)$ & $22(47.8)$ & 0.835 \\
30-Day mortality & $50(63.3)$ & $18(54.5)$ & $32(69.6)$ & 0.172 \\
\hline ICU mortality & $50(63.3)$ & $18(54.5)$ & $32(69.6)$ & 0.172 \\
\hline In hospital mortality & $52(66.7)$ & $19(59.4)$ & $33(71.7)$ & 0.255 \\
\hline Mean VFD at day 30, day & $4.8 \pm 9.2$ & $7.7 \pm 10.8$ & $2.7 \pm 7.3$ & 0.014 \\
\hline Mean ICU-free day at day 30, day & $4.2 \pm 8.3$ & $6.9 \pm 9.8$ & $2.2 \pm 6.5$ & 0.009 \\
\hline
\end{tabular}

Values are presented as number (\%) otherwise indicated.

ICU: intensive care unit; VFD: ventilator free day. 
Table 4. The univariate and multivariate analysis for factors associated with 30-day mortality

\begin{tabular}{|c|c|c|c|c|c|c|}
\hline \multirow{2}{*}{ Variable } & \multicolumn{3}{|c|}{ Univariate } & \multicolumn{3}{|c|}{ Multivariate } \\
\hline & HR & 95\% CI & p-value & HR & $95 \%$ CI & p-value \\
\hline Age & 1.017 & $0.995-1.040$ & 0.137 & 1.007 & $0.982-1.033$ & 0.592 \\
\hline Male sex & 0.953 & $0.526-1.727$ & 0.875 & 0.807 & $0.439-1.484$ & 0.490 \\
\hline APACHE II & 1.073 & $1.025-1.122$ & 0.002 & 1.073 & $1.025-1.122$ & 0.002 \\
\hline RRT & 1.014 & $0.539-1.908$ & 0.966 & 0.830 & $0.422-1.634$ & 0.590 \\
\hline Vitamin $\mathrm{B} 1$ and $\mathrm{C}$ & 0.737 & $0.414-1.314$ & 0.302 & 0.853 & $0.435-1.674$ & 0.644 \\
\hline Steroid & 0.979 & $0.562-1.705$ & 0.941 & 1.018 & $0.540-1.922$ & 0.955 \\
\hline Prone position & 0.684 & $0.291-1.608$ & 0.384 & 0.886 & $0.357-2.198$ & 0.793 \\
\hline
\end{tabular}

HR: hazard ratio; CI: confidence interval; APACHE: Acute Physiology and Chronic Health Evaluation; RRT: renal replacement therapy.

\section{Clinical outcomes and factors associated with 30-day mortality}

The clinical outcomes are shown in Table 3. There were no significant differences in the rates of mortality between two groups. Both mean ventilator-free and ICU-free days at day 30 were significantly longer in the supplementation group than that in the control group $(7.7 \pm 10.8$ days vs. $2.7 \pm 7.3$ days, $\mathrm{p}=0.014$ and $6.9 \pm 9.8$ days vs. $2.2 \pm 6.5$ days, $\mathrm{p}=0.009$ ).

The factors associated with 30-day mortality were evaluated using Cox proportional hazards regression analysis and are shown in Table 4. On univariate and multivariate analyses, APACHE II score was associated with 30-day mortality (hazard ratio [HR], 1.073; confidence interval [CI], 1.025-1.122; $\mathrm{p}=0.002$ ). Supplementation of vitamin B1 and C showed no association with 30-day mortality.

Propensity score matching yield 21 pairs of supplemented and control patients who had similar characteristics including age, sex, APACHE II score, SOFA score, use of NM blockers, steroid, and prone position. In matched patients, there were no significant differences in 30-day morality between supplementation and control group ( $57.1 \%$ vs. $66.7 \%$, $\mathrm{p}=0.525$ ). Both mean ventilator-free and ICU-free days at day 30 were a longer trend toward supplementation group than control group, respectively $(7.3 \pm 11$ days vs. $2.4 \pm 7.7$ days, $\mathrm{p}=0.079$ and $6.9 \pm 9.8$ vs. $2.2 \pm 6.5, p=0.096$ ). Propensity matched analysis also showed that supplementation of vitamin $\mathrm{B} 1$ and $\mathrm{C}$ was not associated with 30-day mortality (HR, 0.808; 95\% CI, $0.377-$ $1.730 ; \mathrm{p}=0.808)$.

\section{Discussion}

In the current study, supplementation of vitamin B1 (200 $\mathrm{mg}$ /day) and vitamin C ( $2 \mathrm{~g} /$ day $)$ showed no improvement in the mortality of patients with sepsis-related ARDS. The mean ventilator-free and ICU-free days at day 30 were longer in patients supplemented with vitamin $\mathrm{B} 1$ and $\mathrm{C}$ than that in the control patients but in matched group, there were no significant different. APACHE II score was associated with the 30day mortality; however, supplementation with vitamin B1 and $\mathrm{C}$ showed no effect on 30-day mortality.

Sepsis is a common condition for ICU admission and accounts for a substantial mortality rate in critically ill patients ${ }^{1}$. ARDS is one of the life-threatening organ dysfunctions in sepsis $^{20}$. The prevalence of ARDS was about $10 \%$ of all ICU admissions and mortality rate was high up to $40 \%$ in severe case $^{2}$. Systemic inflammation is one of the pathogenetic mechanisms in sepsis-related ARDS ${ }^{21,22}$. Inflammation also plays a role in the generation of oxidative stress. Severe lung injury due to inflammation causes hypoxemia, which eventually causes the dysfunction of aerobic metabolism. Mitigation of inflammatory and oxidative stress and facilitation of aerobic metabolism are presumably important to improve the clinical outcomes in patients with sepsis-related ARDS. Protective mechanical ventilation has been advanced to improve the clinical outcome in patients with ARDS. However, clinical trials assessing the efficacy of adjunct pharmacotherapy showed no consistent association with reduced mortality rate of patients with $\mathrm{ARDS}^{5-7}$.

Vitamin C is hydrophilic and excreted in urine and has multiple effects such as anti-inflammation, anti-oxidation, etc. ${ }^{23}$. Vitamin $C$ is a cofactor for an enzyme which activates the endogeneous catecholamine production pathway ${ }^{24}$. Vitamin B1 (thiamine) is a water-soluble and crucial vitamin for aerobic metabolism. It is a cofactor for pyruvate dehydrogenase, which converts pyruvate into acetyl-coenzyme A to enter the tricarboxylic acid cycle ${ }^{8}$. Moreover, vitamin B1 reduces oxalate excretion by acting as coenzyme in vitamin $\mathrm{C}$ metabolism ${ }^{23}$.

Some studies have reported that low vitamin $\mathrm{C}$ level in critically ill patients ${ }^{12}$. Vitamin C deficiency is associated with coagulation abnormalities, and endothelial dysfunction ${ }^{25}$. Vitamin B1 deficiency has been reported approximately up to $70 \%$ of critically ill patients and may be associated with increased mortality ${ }^{26}$. One study reported that thiamine supplementation was associated with lower creatinine levels and 
a lower rate of progression on renal replacement therapy in patients with septic shock ${ }^{27}$. Another study reported that early thiamine administration in patients with septic shock is associated with reduced 28-day mortality ${ }^{28}$.

Two retrospective studies (one on septic shock and the other on severe pneumonia) reported that combined administration of vitamin B1, C, and hydrocortisone was associated with improved clinical outcomes ${ }^{13,14}$. However, two recent studies demonstrated no such clinical benefits of early vitamin $\mathrm{C}$ and thiamine administration in patients with septic shock in emergency department ${ }^{15,16}$. Vitamin C monotherapy was ineffective to improve clinical outcome in patients with severe sepsis or septic shock receiving mechanical ventilation ${ }^{29}$. The clinical implication of combined vitamin $\mathrm{B} 1$ and $\mathrm{C}$ administration and the optimal dose remains undefined. The clinical data of vitamin $\mathrm{B} 1$ and $\mathrm{C}$ supplementation on patients with sepsisrelated ARDS are still lacking. The present study evaluated the clinical benefit of vitamin $\mathrm{B} 1$ and $\mathrm{C}$ supplementation in patients with sepsis-related ARDS. There were no significant differences in mortalities between the supplementation and control groups. The ventilator-free and ICU-free days at day 30 were significantly longer in supplementation group than those in the control group. However, there was no significant different in 21 matched patients using propensity score matching method. Patients in control group were older and had more the proportion of comorbid diseases than those in supplementation group. This might affect the ventilator-free day and ICU-free day in unmatched groups. On multivariate analyses, the severity of illness was associated with 30-day mortality, but not with vitamin $\mathrm{B} 1$ and $\mathrm{C}$ supplementation. The current study showed no improvement in the mortality of patients with ARDS in the supplementation group, which contradicts the results of previous retrospective studies. The following reasons may explain the incongruence of results. First, different characteristics of patients may be different among the studies. Second, the dose of vitamin B1 and C administered was lower than that administered in the previous studies. The current guideline did not support the administration of high doses vitamin, although the administration of high dose vitamin C ( $\geq 3 \mathrm{~g} /$ day) was associated with reduced mortality rate in some studies. Third, all patients assessed in this study did not receive steroid administration whereas most of patients in the two previous studies received steroid administration. Although, theoretically, the combined use of corticosteroid and vitamin $\mathrm{C}$ has a synergistic effect, the current sepsis guideline does not recommend corticosteroid administration except in case of refractory hypotension. The clinical benefit of steroid administration in patients with ARDS is still controversial. Steroid was used in patients with refractory septic shock, exacerbation of existing airways disease. The use of steroid in ARDS was determined by the attending physician.

The current study has several limitations. The first, because of the single center, retrospective study design, selection bias cannot be excluded. The second, some patient did not receive vitamin $\mathrm{B} 1$ and $\mathrm{C}$ administration during supplementation period, which limits the general interpretation of clinical outcomes of the present study. The third, we did not supplement high dose vitamin $\mathrm{B} 1$ and $\mathrm{C}$ as previous studies. The optimal dose of vitamin $\mathrm{Bl}$ and $\mathrm{C}$ supplementation was not defined, and moreover, the current guidelines does not recommend administration of high doses of vitamin B1 and C. The fourth, the biological levels of vitamin $\mathrm{B} 1$ and $\mathrm{C}$ were not measured. Patients with low vitamin B1 and C levels might, therefore, have more clinical benefits than those with sufficient serum vitamin B1 and C levels. The fifth, all patients in the vitamin B1 and $\mathrm{C}$ supplementation group did not get steroids.

In conclusion, vitamin B1 (200 mg/day) and C (2 g/day) supplementation in patients with sepsis-related ARDS requiring invasive mechanical ventilation was not associated with reduced mortality rates, ventilator and ICU-free days. This finding suggests $2 \mathrm{~g}$ /day of vitamin $\mathrm{C}$ is inadequate to show survival benefit in patients with sepsis-related ARDS. Large prospective randomized controlled studies will be needed to conclusively verify the clinical benefit of vitamin $\mathrm{Bl}$ and $\mathrm{C}$ supplementation in patients with sepsis-related ARDS.

\section{Authors' Contributions}

Conceptualization: Yoo JW. Methodology: Yoo JW. Formal analysis: Yoo JW, Kim RB. Data curation: Ju S, Lee SJ, Cho YJ, Jeong YY, Lee JD. Validation: Yoo JW, Kim HC. Investigation: Lee JD, Kim HC. Writing - original draft preparation: Yoo JW. Writing - review and editing: Yoo JW. Approval of final manuscript: all authors.

\section{Conflicts of Interest}

No potential conflict of interest was reported by the authors.

\section{Funding}

No funding to declare.

\section{References}

1. Singer M, Deutschman CS, Seymour CW, Shankar-Hari M, Annane D, Bauer M, et al. The Third International Consensus Definitions for Sepsis and Septic Shock (Sepsis-3). JAMA 2016;315:801-10.

2. Bellani G, Laffey JG, Pham T, Fan E, Brochard L, Esteban A, et al. Epidemiology, patterns of care, and mortality for patients with acute respiratory distress syndrome in intensive care 
units in 50 countries. JAMA 2016;315:788-800.

3. Parhar KK, Zjadewicz K, Soo A, Sutton A, Zjadewicz M, Doig L, et al. Epidemiology, mechanical power, and 3-year outcomes in acute respiratory distress syndrome patients using standardized screening: an observational cohort study. Ann Am Thorac Soc 2019;16:1263-72.

4. Reiss LK, Schuppert A, Uhlig S. Inflammatory processes during acute respiratory distress syndrome: a complex system. Curr Opin Crit Care 2018;24:1-9.

5. Steinberg KP, Hudson LD, Goodman RB, Hough CL, Lanken PN, Hyzy R, et al. Efficacy and safety of corticosteroids for persistent acute respiratory distress syndrome. N Engl J Med 2006;354:1671-84.

6. National Heart, Lung, and Blood Institute ARDS Clinical Trials Network; Truwit JD, Bernard GR, Steingrub J, Matthay MA, Liu KD, et al. Rosuvastatin for sepsis-associated acute respiratory distress syndrome. N Engl J Med 2014;370:2191-200.

7. Gao Smith F, Perkins GD, Gates S, Young D, McAuley DF, Tunnicliffe W, et al. Effect of intravenous beta-2 agonist treatment on clinical outcomes in acute respiratory distress syndrome (BALTI-2): a multicentre, randomised controlled trial. Lancet 2012;379:229-35.

8. Attaluri P, Castillo A, Edriss H, Nugent K. Thiamine deficiency: an important consideration in critically ill patients. Am J Med Sci 2018;356:382-90.

9. Carr AC, Maggini S. Vitamin C and immune function. Nutrients 2017;9:1211.

10. Berger MM, Oudemans-van Straaten HM. Vitamin C supplementation in the critically ill patient. Curr Opin Clin Nutr Metab Care 2015;18:193-201.

11. Donnino MW, Carney E, Cocchi MN, Barbash I, Chase M, Joyce N, et al. Thiamine deficiency in critically ill patients with sepsis. J Crit Care 2010;25:576-81.

12. Carr AC, Rosengrave PC, Bayer S, Chambers S, Mehrtens J, Shaw GM. Hypovitaminosis C and vitamin C deficiency in critically ill patients despite recommended enteral and parenteral intakes. Crit Care 2017;21:300.

13. Marik PE, Khangoora V, Rivera R, Hooper MH, Catravas J. Hydrocortisone, vitamin $\mathrm{C}$, and thiamine for the treatment of severe sepsis and septic shock: a retrospective before-after study. Chest 2017;151:1229-38.

14. Kim WY, Jo EJ, Eom JS, Mok J, Kim MH, Kim KU, et al. Combined vitamin $\mathrm{C}$, hydrocortisone, and thiamine therapy for patients with severe pneumonia who were admitted to the intensive care unit: Propensity score-based analysis of a beforeafter cohort study. J Crit Care 2018;47:211-8.

15. Shin TG, Kim YJ, Ryoo SM, Hwang SY, Jo IJ, Chung SP, et al. Early vitamin $\mathrm{C}$ and thiamine administration to patients with septic shock in emergency departments: propensity score- based analysis of a before-and-after cohort study. J Clin Med 2019;8:102.

16. Litwak JJ, Cho N, Nguyen HB, Moussavi K, Bushell T. Vitamin C, Hydrocortisone, and thiamine for the treatment of severe sepsis and septic shock: a retrospective analysis of real-world application. J Clin Med 2019;8:478.

17. Fan E, Brodie D, Slutsky AS. Acute respiratory distress syndrome: advances in diagnosis and treatment. JAMA 2018;319: 698-710.

18. Singer P, Berger MM, Van den Berghe G, Biolo G, Calder P, Forbes A, et al. ESPEN guidelines on parenteral nutrition: intensive care. Clin Nutr 2009;28:387-400.

19. de Grooth HJ, Manubulu-Choo WP, Zandvliet AS, Spoelstrade Man AME, Girbes AR, Swart EL, et al. Vitamin C pharmacokinetics in critically ill patients: a randomized trial of four IV regimens. Chest 2018;153:1368-77.

20. Mikkelsen ME, Shah CV, Meyer NJ, Gaieski DF, Lyon S, Miltiades AN, et al. The epidemiology of acute respiratory distress syndrome in patients presenting to the emergency department with severe sepsis. Shock 2013;40:375-81.

21. Englert JA, Bobba C, Baron RM. Integrating molecular pathogenesis and clinical translation in sepsis-induced acute respiratory distress syndrome. JCI Insight 2019;4:e124061.

22. Matthay MA, Zemans RL, Zimmerman GA, Arabi YM, Beitler JR, Mercat A, et al. Acute respiratory distress syndrome. Nat Rev Dis Primers 2019;5:18.

23. Marik PE. Vitamin C for the treatment of sepsis: the scientific rationale. Pharmacol Ther 2018;189:63-70.

24. Carr AC, Shaw GM, Fowler AA, Natarajan R. Ascorbatedependent vasopressor synthesis: a rationale for vitamin $\mathrm{C}$ administration in severe sepsis and septic shock? Crit Care 2015;19:418.

25. Marik PE, Hooper MH. Doctor-your septic patients have scurvy! Crit Care 2018;22:23.

26. Cruickshank AM, Telfer AB, Shenkin A. Thiamine deficiency in the critically ill. Intensive Care Med 1988;14:384-7.

27. Moskowitz A, Andersen LW, Cocchi MN, Karlsson M, Patel $\mathrm{PV}$, Donnino MW. Thiamine as a renal protective agent in septic shock: a secondary analysis of a randomized, doubleblind, placebo-controlled trial. Ann Am Thorac Soc 2017;14: 737-41.

28. Woolum JA, Abner EL, Kelly A, Thompson Bastin ML, Morris PE, Flannery AH. Effect of thiamine administration on lactate clearance and mortality in patients with septic shock. Crit Care Med 2018;46:1747-52.

29. Ahn JH, Oh DK, Huh JW, Lim CM, Koh Y, Hong SB. Vitamin C alone does not improve treatment outcomes in mechanically ventilated patients with severe sepsis or septic shock: a retrospective cohort study. J Thorac Dis 2019;11:1562-70. 